\title{
THE LAND-COVER CASCADE: RELATIONSHIPS COUPLING LAND AND WATER
}

\author{
C. L. Burcher, ${ }^{1}$ H. M. Valett, and E. F. Benfield \\ Department of Biological Sciences, Virginia Tech, Blacksburg, Virginia 24061 USA
}

\begin{abstract}
We introduce the land-cover cascade (LCC) as a conceptual framework to quantify the transfer of land-cover-disturbance effects to stream biota. We hypothesize that disturbance is propagated through multivariate systems through key variables that transform a disturbance and pass a reorganized disturbance effect to the next hierarchical level where the process repeats until ultimately affecting biota. We measured 31 hydrologic, geomorphic, erosional, and substrate variables and 26 biotic responses that have been associated with landuse disturbance in third- and fourth-order streams in the Blue Ridge physiographic province in western North Carolina (USA). Regression analyses reduced this set of variables to include only those that responded to land cover and/or affected biota. From this reduced variable set, hypotheses were generated that predicted the disturbance pathways affecting each biotic response following the land-cover-cascade design. Cascade pathways began with land cover and ended with biotic responses, passing through at least one intermediate ecosystem abiotic component. Cascade models were tested for predictive ability and goodness-of-fit using path analysis. Biota were influenced by near-stream urban, agricultural, and forest land cover as propagated by hydrologic (e.g., discharge), geomorphic (e.g., stream bank height), erosional (e.g., suspended sediments), and depositional streambed (e.g., substrate size) features occurring along LCC pathways, reflecting abiotic mechanisms mediating land-cover disturbance. Our results suggest that communities are influenced by land-cover change indirectly through a hierarchy of associated abiotic components that propagate disturbance to biota. More generally, the land-cover cascade concept and experimental framework demonstrate an organized approach to the generic study of cascades and the complex relationships between landscapes and streams.
\end{abstract}

Key words: disturbance; geomorphology; GIS; hydrology; land-cover cascade; sediment; watershed.

\section{INTRODUCTION}

Ecosystem responses to disturbance vary due to the changing nature, intensity, and duration of the disturbance regime and patterns or conditions of ecosystem recovery (Lake 2000, Allan 2004). Identifying mechanisms that differentially translate disturbance into structural and functional change is crucial for the development of a watershed-scale conceptual framework for ecological exploration, as well as informing socioeconomic decisions concerning ecosystem management and conservation. Stream ecosystems integrate the landscapes they drain in terms of water transport (Hynes 1975, Doyle et al. 2005) and respond to changing terrestrial conditions (Likens et al. 1984). As such, multiple pathways of change within catchments influence stream structure and function.

Many studies have shown that land cover induces hydrologic, geomorphic, erosional, and biotic responses (Waters 1995, Richards et al. 1996, Harding et al. 1999,

Manuscript received 17 November 2005; revised 1 June 2006; accepted 19 June 2006. Corresponding Editor: C. R. Hupp.

${ }^{1}$ Present address: Department of Biology, Marshall University, One John Marshall Drive, Huntington, West Virginia 25755 USA. E-mail: burcher@marshall.edu
Cuffney et al. 2000, Lee and Bang 2000) and correlates with ecosystem structure and function (Meyer and Turner 1992, Jacobson et al. 2001). Much of what we know about anthropogenic disturbance suggests direct, bivariate (i.e., comparisons between an independent and dependent variable) effects of land cover on biota, but these models fail to explain the disturbance pathways involved because they do not integrate multiple scales (Downes et al. 2002) and do not address mechanisms that generate observed responses. For example, agriculture has been associated with lower invertebrate diversity but agriculture cannot be the immediate cause and must be delivered by intermediate variables. Without knowing how agricultural influence is propagated through a system we cannot identify the associated mechanisms, thus reducing our ability to understand or manage agricultural systems. We use the cascade approach to identify the parts through which influence is propagated in a system.

\section{Components of ecological cascades}

Generally, cascades describe a series of components and the output of each component serves as the input for the next. Inherent to many cascade definitions is the idea of falling from one level to the next in a series. Emergent properties of cascades include obligatory 
TABLE 1. Glossary of terms used to describe ecological cascades.

\begin{tabular}{|c|c|}
\hline Term & Definition \\
\hline Stimulus & Hypothesized cause that initiates a cascade \\
\hline Response & Terminal changes in specified variables of interest that represent the endpoint of a cascade \\
\hline Element & $\begin{array}{l}\text { Components of a cascade defining specific characteristics and associated spatial scale represented by one or } \\
\text { more entities }\end{array}$ \\
\hline Entity & $\begin{array}{l}\text { Component of an element that responds to the influence of other entities in previous elements or within the } \\
\text { same element and translates these responses as causes that influence successive entities }\end{array}$ \\
\hline Couple & $\begin{array}{l}\text { Interactions among entities where influence is delivered to an entity (cause), translated, and exported as an } \\
\text { effect that will influence a successive entity }\end{array}$ \\
\hline Cause & Influence from one entity to another (input) that may be translated to an effect (output) \\
\hline Effect & The influence (output) from a given entity, generated by translation of a cause (input) \\
\hline Translation & The mechanism by which an entity transforms an influence from one entity to an influence on another \\
\hline Link & A couple that includes entities in different elements; a coupling between elements \\
\hline Pathway & A series of connected links or couples \\
\hline Cascade & A pathway originating with the stimulus and terminating in the response \\
\hline
\end{tabular}

Note: Functional relationships among terms are illustrated in Fig. 2.

relationships among components and can be thought of as propagation pathways that organize the transfer of an effect. Cascades have been used to describe several biological relationships including enzymatic cascades, electron transfer, and trophic cascades that describe relationships between producers and consumers. We use the term cascade to describe a pathway where a stimulus is propagated through a series of variables and terminates in a response.

While the idea of an ecological cascade is well developed heuristically, here we provide a conceptual scheme to render it broadly operational and illustrate this approach in the context of land-use influences on stream biota. Reiners and Driese (2000) initiated a formal etymology describing the propagation of phenomena similar to cascades. We build on their language and supply more explicit terminology to describe the processes involved in propagation (Table 1).

Elements and entities.-Biological cascades organize how a stimulus is propagated through a series of interdependent elements to evoke an eventual response in a defined variable or suite of variables (Fig. 1A). A stimulus is defined as the hypothesized or suspected cause of the series of interactions described by the cascade that ultimately results in a response (i.e., the terminal effect of interest). Typically, elements are identified according to the available information about a particular system and may be of physical, chemical, or biological composition. Elements are arranged at well-known levels of organization (e.g., communities, species, organs, or enzymes) but may be physical (land vs. water) or chemical (organic vs. inorganic) when considering ecosystem or landscape cascades. Elements are composed of entities, which consist of quantifiable components occurring at the spatial scale of a given element. For example, an element may be a community and within that community, species may be entities quantified by their abundance. Entities are also defined by an investigator in the context of the question of interest and should be well-understood components relevant to a particular cascade. Many entities can comprise an element, but all entities must be defined within the same organizing constraints, otherwise they are assigned to a different element.

Translation and couples.-Relationships among entities serve to transmit the stimulus through the cascade. Couples occur where an entity interacts with another entity, stimulus, or response. One entity provides an effect that induces a reaction in another entity, which transforms the influence and communicates a novel effect as a cause influencing a different entity. The stimulus is initially delivered to an entity that receives, processes, and transmits the influence as a new effect. Hence, we reserve the use of the term "stimulus" to denote the initial influence of interest. The influences of stimuli are thus transmitted through cascades via translation, whereby a given entity receives effects from an adjacent entity (or from the initial stimulus), translates the effect to an internal cause, then exports the new effect to an adjacent entity (or an entity in another element). Entities, therefore, are the structural elements of cascades, among which functional relationships exist to create couples, links, and pathways.

Links and pathways.-Links, specific examples of couples, are defined as the receipt, processing (i.e., translation), and subsequent delivery of an effect between entities residing in different elements. Links serve to propagate the original stimulus across elements. Multiple conterminous couples or links form pathways and represent mechanistic routes that translate a stimulus to associated elements and entities.

\section{Emergent characteristics of cascades}

At a minimum, a cascade is composed of two links including a single element composed of one entity that occurs between a stimulus and response. Cascades comprised of multiple elements have the potential to have a greater number of links. A complete cascade is described by a pathway that includes the stimulus, all intervening elements, and the response. It is possible for a cascade to pass through fewer than the maximum number of elements. These are low-order cascades where order is defined by the number of links involved. First- 

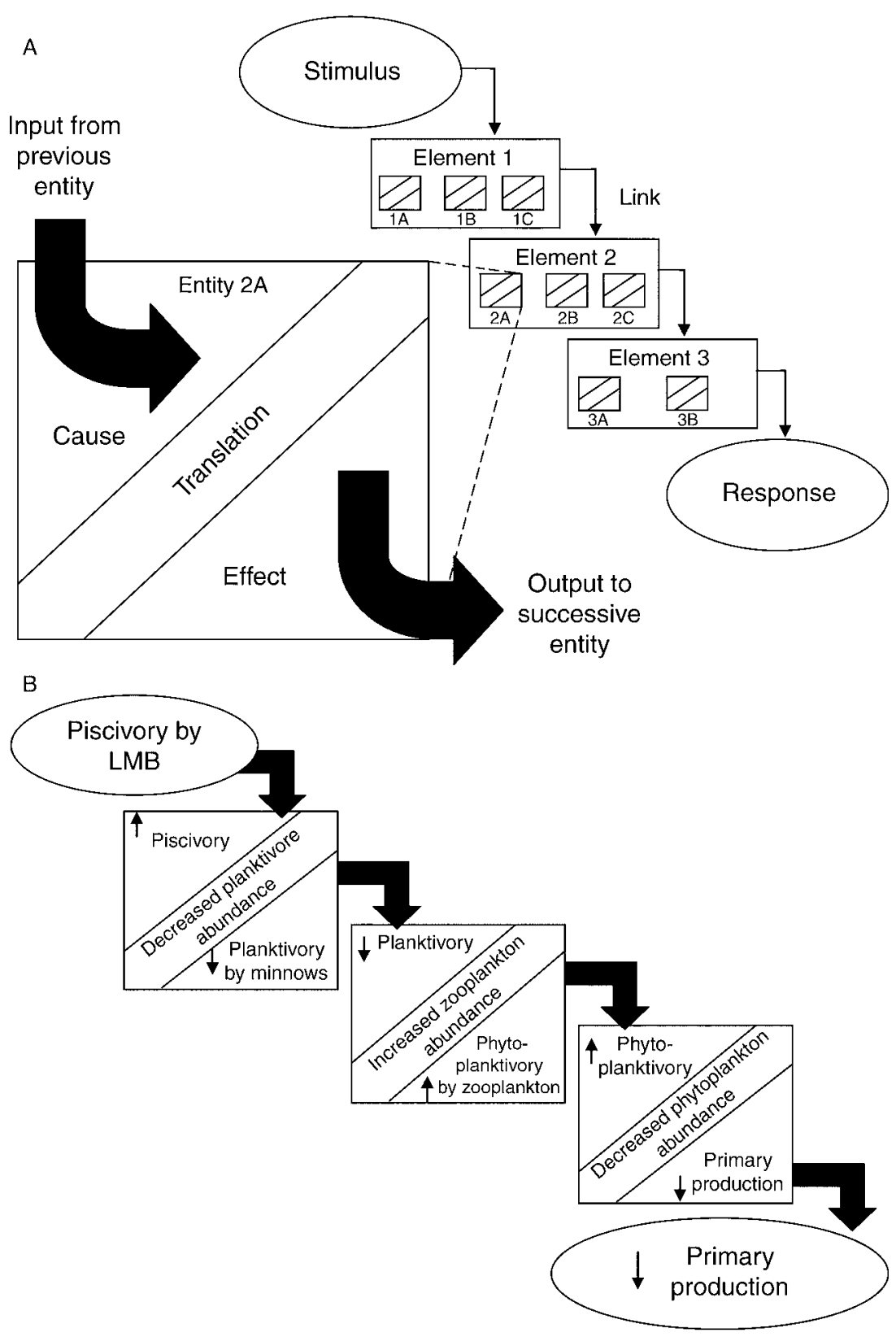

FIG. 1. (A) Illustration showing propagation of a stimulus through a cascade and demonstrating translation. At least one entity in each element (1-3) must interact with at least one other entity or the stimulus or the response to complete the cascade. (B) As an example, a typical lentic trophic cascade is shown using cascade terminology. The stimulus of bass (LMB) predation is propagated via trophic interactions to induce the response of decreased primary productivity and clearer water.

order cascades pass through a single element, secondorder cascades pass through two elements, and so on. For example, a cascade consisting of three elements has four possible links. For that system, a second-order cascade passes through two links, a third-order cascade passes through three, and a fourth-order cascade would be referred to as complete.

\section{An example: trophic cascades}

Perhaps the most common use of the cascade approach in ecology is the trophic cascade (Fig. 1B;
Carpenter et al. 1985). The response of interest, in this case, is water clarity and a fourth-order cascade describes how smallmouth bass predation stimulates reduced primary productivity and lowers turbidity. Predatory stimulus decreases zooplanktivory by reducing minnow abundance. In turn, reduced zooplanktivory induces an increase to zooplankton abundance and increased grazing. Higher grazing propagates to reduce phytoplankton abundance, and as a response, water is less turbid. In this example, the cascade approach explains how entities (minnows, zooplankton, and 


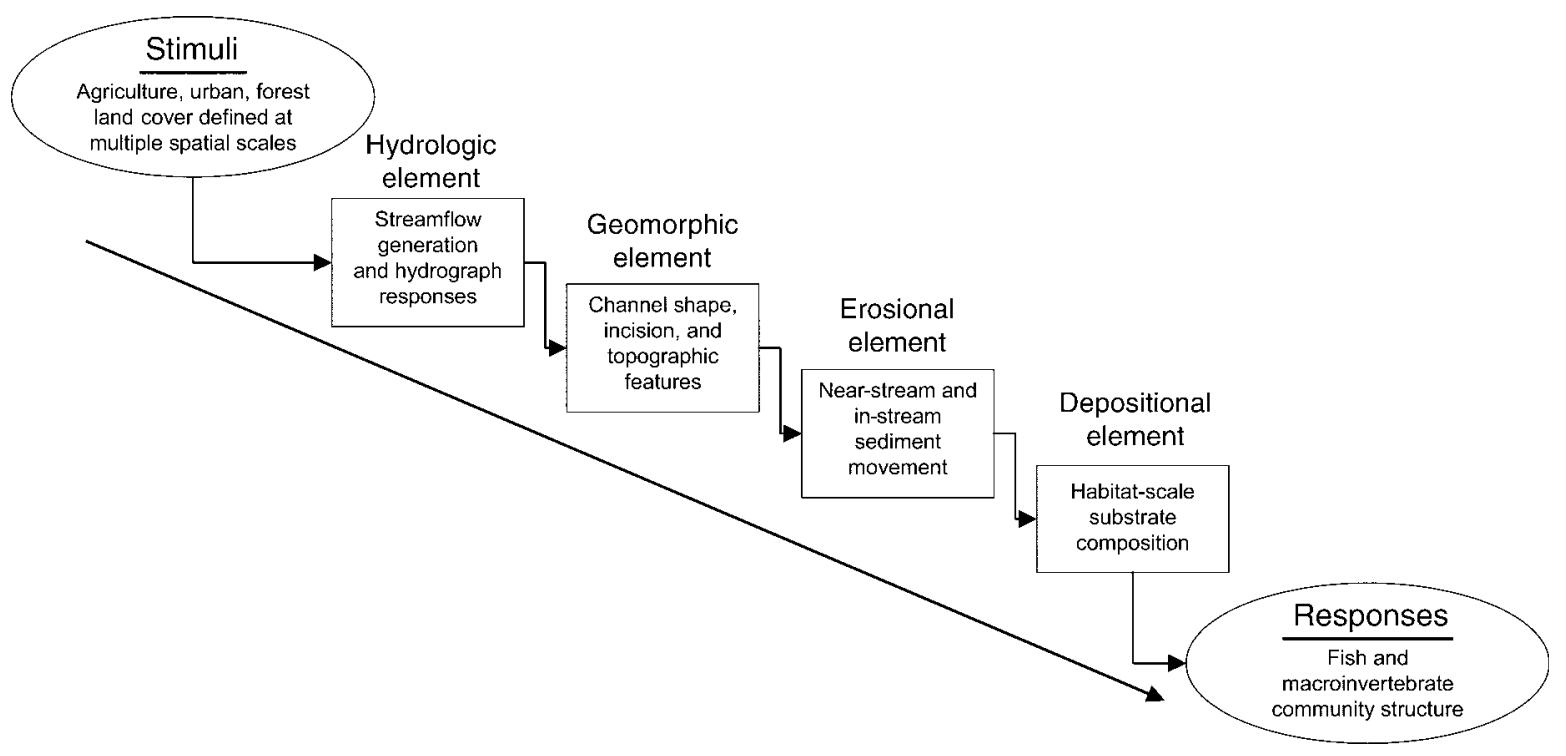

FIG. 2. Schematic describing the general land-cover cascade (LCC) hypothesis linking land-cover disturbance to biotic responses via hydrologic, geomorphic, erosional, and depositional elements. Text inside each box describes the general characteristics of entities within each element. Path arrows represent mechanistic cause-effect-cause links between elements, stimuli, and responses.

phytoplankton) that do not directly interact can indirectly influence each other through a series of multiple propagation steps.

\section{Constructing the land-cover cascade}

The land-cover cascade (LCC) assumes a physically based approach whereby the watershed is the "grand scale," driving hierarchical, scalar relationships that cascade to communities (Allan 2004). The LCC reflects dynamic interactions that integrate recent time and space. In other words, links represent responses of entities that reflect recent and historic interactions. For example, statically measured geomorphic entities necessarily reflect the past flow regime, and the presence of taxa reflect their ability to tolerate or avoid catastrophic flows. In developing the LCC approach, we followed the ecologically effective discharge concept (Doyle et al. 2005), whereby baseflow discharge represented the effective condition of transport of suspended materials and regulation of habitat. Here we employ the cascade approach to organize how land-cover disturbance within watersheds is transferred across multiple spatial scales to influence biotic diversity and community structure of stream fauna (Fig. 2). The LCC is a conceptual design used to address relationships among a series of compartments through which land-cover disturbance at the watershed and sub-watershed scales is propagated and organized along a gradient of reducing spatial scales similar to the process-domain concept (Montgomery 1999). Thus, the LCC is a hierarchical cascade that spans spatial scales from individuals to ecosystems and incorporates landscape, reach, and habitat scale phenomena.
To build specific LCC models, we identified either four or five elements between land cover and biota: hydrologic, geomorphic, erosional, depositional, and, for macroinvertebrate models, fish. Land-cover stimuli describe landscape features at the watershed and subwatershed scales. Hydrologic entities were defined within the spatial scale appropriate to summarize ecosystem hydrology, including streamflow generation and hydrograph responses to rainfall. Geomorphic entities were defined at the channel reach scale ranging from 50 to $1000 \mathrm{~m}$ in length. Erosional entities reflected proximal riparian areas and immediate stream channels close to sample areas (i.e., 5-20 m). Depositional entities described the habitat or patch scale immediately contiguous with biota $(<1 \mathrm{~m})$.

The LCC implies that land-cover effects and biota interact indirectly through at least one intermediate element or entity and link. For example, stream fishes have been linked to hydrologic patterns (Poff and Allan 1995), geomorphic features (Lamouroux et al. 2002), and habitat stability (Richards et al. 1996). We predicted that LCC models linking fish density to land use would include hydrologic entities (e.g., stormflow discharge) directly influenced by land cover, geomorphic entities (e.g., channel incision or bank height), and likely the influence of erosional or depositional substrates due to fish associations with habitat. Further, we expected the representation of fish feeding habits to reflect availability of prey items associated with the hydrologic regime and substrate composition.

Macroinvertebrates have strong associations with micro-habitat (Resh and Rosenberg 1984) and contribute greatly to fish diets (Jenkins and Burkhead 1994). 
We also predicted that macroinvertebrate metrics would respond to depositional substrate characteristics. Substrata have been shown to be largely organized by hydrologic patterns and erosion. Thus, we predicted that macroinvertebrate structure would be best explained by LCC models linking land use to substrate through hydrologic entities.

Our application of a cascade approach to land-cover influences on streams is twofold: (1) to illustrate the general utility of quantifying the character of cascades and (2) to facilitate identification of mechanisms that translate terrestrial disturbance to its ultimate influence on aquatic biota. We propose that the LCC offers a powerful conceptual framework to predict how a disturbance regime may govern ecosystem structure and function.

\section{Methods \\ Study sites}

Abiotic and biotic LCC entities were measured in 10 third- or fourth-order streams in the Blue Ridge physiographic province in western North Carolina, USA, which had been historically influenced by row crop and grazing agriculture. Streams were comparable in length, gradient, and underlying geology (for site locations see Burcher and Benfield [2006]). Watershed areas varied from 1000 to 3500 ha (1907 \pm 256 ha, mean $\pm \mathrm{SE})$. All watersheds contained agricultural areas active since at least 1950 and varied from $21 \%$ to $77 \%$ $(47 \% \pm 18 \%$, mean $\pm \mathrm{SE})$ in agricultural land cover and $16-62 \%(40 \% \pm 14 \%$, mean \pm SE) as forested as of 1992 (Herman 1996, Wear and Bolstad 1998, USCB 2002).

\section{Land cover}

Land-cover variables (from 1992) were treated as cascade stimuli and were estimated from the MultiResolution Land Characteristics Consortium (MRLC) National Land Cover Database (NLCD; USDI 2002). Whole-watershed land-cover classification was calculated as the percentage of a land-cover type in the entire watershed area. Eleven NLCD land-cover categories were combined to generate four land-cover types: agriculture, urban, forest, and "other" (Appendix A). The 11 categories were the result of a combination of forest vegetation types, a gradient of urban development, and rare or atypical land cover (i.e., open water or barren, rocky areas). The agriculture land-cover type included active row crops, grazing areas, and old fields. The urban land-cover type included urban and developed rural areas in addition to roads and other elements of human infrastructure. Forest combined most vegetation categories, and the "other" category included open water, barren areas, and rare land-cover descriptors that did not fit into the previous categories.

Several authors have shown that biotic responses differentially relate to land cover defined at different ecological scales (Harding et al. 1998, Sponseller et al. 2001). To address the variation in land-cover influence with distance from streams, we quantified land cover along a spatial gradient from near-stream to wholewatershed areas (Appendix A). We used GIS to delineate/estimate 100-m riparian corridors around each stream and used the corridors to constrain land cover. Land-cover estimates were then calculated as the percentage of each land-cover type within each riparian corridor. To examine land cover along a continuum of spatial proximity to stream channels, overland-flow travel-time estimates were used to constrain the area in which land-cover percentages were estimated and thus how independent variables were defined. Travel-time estimates were calculated using GIS and defined by gradient, surface roughness, average rainfall, and other criteria (Burcher 2005).

\section{Elements and entities}

Entities were established to capture a broad spatial and temporal range of abiotic features shown or inferred to contribute to biotic responses associated with landcover change (Frissell 1986). A total of 43 entities (Appendix B) were assigned to either four or five elements, depending on the designated class of response variables. For LCC models predicting fish assemblage structure, four elements were defined as hydrologic (Hydro), geomorphic (Geo), erosional (Ers), and depositional (Dep). Data on macroinvertebrate communities were not included when constructing LCC models for fish communities. In contrast, fish data represented a fifth element (biota) used to generate LCC models for invertebrate community responses.

Six hydrologic entities were generated to represent landscape scale phenomena, including discharge (measured at various stages) and water-travel-time estimates calculated with GIS. Geomorphic entities (10) were calculated from multiple-channel cross-section surveys, digital elevation models, and line-transect discharge measurements. Erosional entities (11) described mobile components of stream systems and included suspended and bedload sediment concentration and standing stock of fine benthic organic matter (FBOM; $<0.1 \mathrm{~mm}$ in diameter). Depositional entities (three) quantified stream-bed particle size and percentage of substrate present as FBOM.

\section{Field data collection}

Entities.-Empirical rating curves were generated from multiple field measurements relating discharge (Marsh-McBirney flow meter, line-transect method) to stage height (measured from permanent survey points) and used to generate hydrologic entities. Geomorphic entities were estimated from three channel cross sections measured twice at each stream. Laser surveying (Topcon, Tokyo, Japan) was conducted to estimate elevation changes in stream banks and the near-stream floodplain. Erosional information was collected by sampling total suspended solids (TSS) multiple times $(n=12-20)$ in each stream using both grab sampling and rising-limb 
sediment collectors (Braatz 1961) to calculate the concentration of sediments in suspension $(\mathrm{mg} / \mathrm{L})$. Bedload particle size and organic matter content was calculated from multiple samples $(n=4-9)$ collected approximately monthly from PVC collection tubes installed in substrata to capture materials moving along streambeds. Depositional metrics were generated from dry-particle sieve analysis. Percentage of organic matter $(\mathrm{OM})$ was estimated for erosional and depositional elements by ash-free dry mass.

Fish assemblages.-Fish were collected in August 2002 using backpack electrofishing, identified to species, and classified by reproductive, trophic, and distributional status (13 total entities or responses; see Appendix B) based on current classifications (Etnier and Starnes 1993, Jenkins and Burkhead 1994). For each response metric, fish density (number of fish per square meter) was estimated as the number of fishes present in a sample reach whose area was calculated as the product of length and average stream width.

Macroinvertebrate assemblages. - In each study stream, 20 quantitative (Surber) samples were randomly assigned within $100-\mathrm{m}$ stream reaches and collected in April 2003. Invertebrate specimens were preserved in $80 \%$ ethanol and identified to genus, except for chironomids, which were identified to family. Macroinvertebrates were placed into functional feeding groups according to Merritt and Cummins (1996) and the respective density for each group was calculated based on the area sampled $\left(0.09 \mathrm{~m}^{2}\right.$ per Surber sample; $1.8 \mathrm{~m}^{2}$ per stream reach). A total of eight possible macroinvertebrate responses were considered (Appendix B).

\section{Statistical analyses}

Reducing the variable set.-To reduce the set of 49 entities potentially participating in the LCC, we used Pearson product moments to assess the strength and direction of significant relationships between entities within each element (SigmaStat version 3.0; SPSS, Chicago, Illinois, USA). We reduced entities within an element when estimates for a given element were highly correlated by selecting the measure most typically used in other studies for further analyses.

Next, every possible pairwise combination of variables was analyzed using simple linear regression to identify underlying bivariate relationships among entities in different elements, land cover, and each biotic response (SigmaStat version 3.0). Land-cover variables (36) were compared to every other abiotic and biotic variable (49) for a total of 1764 comparisons. All abiotic variables (i.e., entities; 28 total) were compared with each biotic (21) variable in 588 comparisons. To generate the largest potential grouping of entities, we employed a conservative approach whereby ecologically significant variables were defined as those that were significantly correlated $(P<0.05)$ to at least one stimulus, entity, or response and contained no visible outliers that drove regressions in scatter-plots. We considered pairwise regressions ecologically significant (i.e., direct effects) where land cover or an abiotic response explained more than $40 \%$ of the variation in abiotic or biotic responses as indicated by the coefficient of determination $\left(r^{2}\right)$. We chose $40 \%$ as our rejection level, to be permissive enough to consider entities that may contribute to a larger model but conservative enough to reduce the number of entities we considered. Variables that failed to meet these criteria in any bivariate comparison were considered unimportant for path development and omitted from further analyses.

Identifying appropriate cascade models.-We used path analysis (Shipley 2000) to test whether hypothesized LCC paths described actual relationships among land-cover, abiotic, and biotic elements. Amos (version 5.0; SPSS, Chicago, Illinois, USA) was used to design and test relationships among stimuli, entities, and responses, and to consider whether or not hypothesized path models fit our data (Arbuckle 2003). For each response variable (biotic entity), we arranged conceivable paths that linked each land-cover category to each response through all possible entities. Paths included at least three variables (stimulus, entity, and response) but could include all variables (as many as seven: one stimulus, five entities, and one response) in the pool available for LCC construction. We then screened pathways between stimuli and responses using EPA2 (Exploratory Path Analysis; Shipley 2000) to eliminate under-identified paths (i.e., paths having more arrows than entities). We next tested each potential path using Amos to identify paths that fit our sample data. Model fit was determined primarily by chi-square analysis, where $P$ values $>0.05$ indicated no significant difference between the model and the data, and those close to 1 were considered excellent fits. We also considered rootmean-squared error approximation (root mean square error of approximation [RMSEA]; where $P<0.05$ indicated no significant difference between the data and the model) and the normed fit index (NFI; where $P>$ 0.9 indicated no significant difference between the data and the model) output from Amos (Arbuckle 2003) as secondary support for model fit.

In addition to assessment of model fit, path analysis output calculates several useful parameters typically displayed in two forms: the illustrated path model containing path coefficients and a tabular summary of direct (bivariate paths leading to response) and indirect (multivariate paths leading to response) effects. Illustrated models show path coefficients next to each arrow linking entities and/or responses that quantify the influence of preceding entities and stimuli for each model component and are analogous to bivariate correlation coefficients. Next to variable boxes, standardized partial regression coefficients (analogous to $R^{2}$ ) quantify the amount of variance in an entity or response explained by the preceding model. Path coefficients indicate Amos-quantified, standardized (i.e., ranging between 0 and 1) bivariate relationships and multivar- 
iate relationships (i.e., more than two variables) within models using path coefficients and squared multiple correlations. Together, these coefficients indicated both the percentage variance in a biotic response that was explained by an entire pathway or path section and the strength and direction of relationships of bivariate comparisons along a significant path. We focused on interpreting path coefficients over direct and indirect effects because we were testing hypotheses about model fit and the relationships among entities, stimuli, and responses (i.e., the existence and character of cascades). Interpretation of direct, indirect, and total effects, on the other hand, emphasizes weighting the contribution of individual model parameters.

\section{RESULTS \\ Reduced variable set}

Correlation analyses reduced our original set of 85 variables (36 land cover, 28 abiotic, and 21 biotic) to 12 land-cover, 16 abiotic, and 14 biotic variables (Table 2). Sixty-nine significant relationships among these variables were identified with linear regression and used to guide our path-model hypotheses (Appendix C). Hydrologic, geomorphic, erosional, and depositional entities were important in at least one pairwise regression. Two-thirds (14 of 21) of the original biotic metrics were retained because they were predicted by stimuli or entities and these variables included both taxonomic and functional metrics for fish and macroinvertebrates.

\section{Significant land-cover cascades}

Land-cover cascades identified seven land-cover, two hydrologic, three geomorphic, two erosional, three substrate, five fish, and seven macroinvertebrate variables as participating in at least one cascade (Appendix D). LCC models predicting 6 of 13 fish (Fig. 3) and seven of eight macroinvertebrate (Fig. 4) response variables were significant and formed disturbance cascades between land-cover and biota. Only one response (macroinvertebrate predators) was not included in a significant path model, despite being significant in at least one linear regression. Each significant path model began with a land-cover stimulus (most commonly agriculture) and included at least one abiotic entity. None of the path models reflected a complete cascade, that is, no paths included an entity from all described elements.

Two LCCs, one predicting fish total density and a second related to macroinvertebrate collector-filterer (CF) density were by far the strongest models. For these LCCs, $P$ values for chi-square exceeded 0.7 while $P$ values for other models ranged from 0.05 to 0.46 with a mean of 0.17 . At the same time, these two models had the lowest recorded root mean square error (RMSE) and were among the highest NFI. Thus, we considered the stimuli and entities associated with these responses to be the most useful in explaining disturbance propagation through study streams.
Fish responses.-Fish responses, in general, were predicted by near-stream agriculture, and fish were not influenced by hydrologic entities (Fig. 3). Agricultural land cover was the stimulus in most models (five of six) whereas urban land cover was important in two models. Agriculture indirectly reduced fish taxa richness, total density, and cosmopolitan density but had a positive effect on nest-associate (NA) and non-guarding (NG) fish density. Percentage of total suspended solids (TSS) inorganic matter (IM) was important in each path except for herbivore and non-guarder density. The influence of agriculture was propagated through geomorphic alteration including bank incision and width: depth ratio. Two cascades included the depositional entities substrate $\mathrm{OM}$ (positively related to NG) and percentage of fines (negatively related to herbivore density).

Fish total density was predicted by the strongest fish cascade path model (chi-square $P>0.7$ ) linking the influence of urban land cover through the erosional element TSS and agricultural land cover via the geomorphic element bank height (Fig. 3B). The fish total density LCC explained $91 \%$ of the variance in fish density among streams and was comprised of two firstorder cascades. Both urban and agricultural land cover had a negative overall influence on fish total density associated with higher baseflow inorganic suspended solids (urban) or channel incision (i.e., increased bank height with agriculture). Agriculture explained $40 \%$ (path coefficient) of the increase in bank height $(+0.64$; direct effect), and bank incision had a negative influence $(-0.69)$ on fish total density. Lower urban land use in 60min travel-time zones (TTZs) increased the concentration of baseflow TSS inorganic matter $(-0.42)$ and explained $18 \%$ of the observed variance in baseflow TSS.

Other significant fish LCC models were less explanatory than the fish-total-density LCC, but patterns inherent to these models provide useful information regarding the internal relationships among stimuli, entities, and responses. Fish taxa richness (Fish S) decreased negatively with near-stream agriculture and stormflow suspended inorganic matter (Fig. 3A). Cosmopolitan fish density decreased with higher agriculture, higher bank height, and lower TSS IM (Fig. 3C). Agriculture and TSS IM $(+0.41)$ had a positive effect on fish nest-associate density. Fish herbivore density was negatively correlated to urban land cover (Fig. 3E), and non-guarder density (Fig. 3F) was positively correlated to agriculture. Both responses were mediated by geomorphic entities (width: depth ratio and change in bank incision ratio, respectively) and depositional entities (substrate fines and OM).

Macroinvertebrate responses.-Macroinvertebrate responses were predicted by higher order models compared to fish LCCs (Fig. 4). Agriculture was the stimulus in five of seven significant LCCs, urban land cover in four LCCs, and forest was the stimulus in one LCC. Agriculture had a negative indirect effect on macroinvertebrate total density, collector-filterer (CF) density, 
TABLE 2. Reduced variables set used to generate LCC models.

\begin{tabular}{|c|c|c|c|c|c|c|}
\hline Metric, by type & $\begin{array}{l}\text { Metric } \\
\text { code }\end{array}$ & $\begin{array}{l}\text { Zone or } \\
\text { units }\end{array}$ & Mean & SE & Minimum & Maximum \\
\hline \multicolumn{7}{|l|}{ Landscape } \\
\hline \multicolumn{7}{|l|}{ Land-cover percentage } \\
\hline & Forest & $60 \mathrm{~min}$ & 46 & 5 & 22 & 84 \\
\hline & & $90 \mathrm{~min}$ & 50 & 5 & 26 & 70 \\
\hline & & $120 \mathrm{~min}$ & 56 & 5 & 30 & 73 \\
\hline & & Corr. & 51 & 3 & 33 & 65 \\
\hline & Agriculture & $60 \mathrm{~min}$ & 42 & 4 & 13 & 65 \\
\hline & & $90 \min$ & 39 & 4 & 28 & 64 \\
\hline & & $120 \mathrm{~min}$ & 35 & 4 & 25 & 63 \\
\hline & & Corr. & 41 & 3 & 24 & 55 \\
\hline & & WS & 23 & 2 & 17 & 36 \\
\hline & Urban & $60 \mathrm{~min}$ & 8 & 4 & 0 & 43 \\
\hline & & $90 \mathrm{~min}$ & 7 & 4 & 0 & 44 \\
\hline & & $120 \mathrm{~min}$ & 6 & 4 & 0 & 38 \\
\hline \multicolumn{7}{|l|}{ Hydrologic } \\
\hline Baseflow discharge & Qbf & $\mathrm{L} / \mathrm{s}$ & 40 & 5.5 & 15 & 67 \\
\hline Mean travel time & MnTT & $\min$ & 146 & 26 & 45 & 264 \\
\hline Discharge/stage rating curve slope & RCsl & $\dagger$ & 0.91 & 0.06 & 0.52 & 1.24 \\
\hline \multicolumn{7}{|l|}{ Geomorphic } \\
\hline Froude number & $\mathrm{Fr}$ & $\dagger$ & 0.124 & 0.015 & 0.06 & 0.21 \\
\hline Mean bank height year one & Bh1 & $\mathrm{m}$ & 1.3 & 0.07 & 1.0 & 1.8 \\
\hline Change in incision ratio between years & $\Delta \mathrm{IR}$ & degrees & 3.5 & 1.5 & 0.5 & 16.3 \\
\hline Mean bankfull width & $\mathrm{w}$ & $\mathrm{m}$ & 4.1 & 0.34 & 1.7 & 5.1 \\
\hline Mean bankfull depth & d & $\mathrm{m}$ & 0.17 & 0.01 & 0.07 & 0.25 \\
\hline Width: depth ratio & $\mathrm{w}: \mathrm{d}$ & $\dagger$ & 29 & 4.8 & 9 & 63 \\
\hline \multicolumn{7}{|l|}{ Erosional } \\
\hline TSS baseflow & TSSbf & $\mathrm{g} / \mathrm{L}$ & 0.37 & 0.23 & 0.01 & 1.29 \\
\hline Baseflow TSS inorganic matter & TSSbfIM & $\mathrm{g} / \mathrm{L}$ & 0.29 & 0.20 & 0.01 & 1.15 \\
\hline Rising limb TSS stormflow & TSSst & $\mathrm{g} / \mathrm{L}$ & 0.48 & 0.28 & 0.01 & 0.57 \\
\hline Stormflow TSS inorganic matter & TSSsfIM & $\mathrm{g} / \mathrm{L}$ & 0.39 & 0.23 & 0.06 & 1.4 \\
\hline \multicolumn{7}{|l|}{ Depositional } \\
\hline Substrate $\mathrm{D}_{50}$ & $\mathrm{SubD}_{50}$ & $\mathrm{~mm}$ & 15.9 & 2.3 & 4.6 & 23.4 \\
\hline Substrate percentage organic matter & SubOM & $\%$ & 6.3 & 0.2 & 5.3 & 7.9 \\
\hline Substrate percentage fines & SubFines & $\%$ & 14 & 2.9 & 2.8 & 27.4 \\
\hline \multicolumn{7}{|l|}{ Fish } \\
\hline \multicolumn{7}{|l|}{ Summary } \\
\hline Taxa richness & FishTR & no. $/ \mathrm{m}^{2}$ & 7.6 & 0.7 & 4 & 11 \\
\hline Total density & FishDen & no. $/ \mathrm{m}^{2}$ & 1.1 & 0.2 & 0.46 & 2.27 \\
\hline \multicolumn{7}{|l|}{ Distributional } \\
\hline Cosmopolitan density & $\operatorname{Cos}$ & no. $/ \mathrm{m}^{2}$ & 1.8 & 0.4 & 0.36 & 2.27 \\
\hline \multicolumn{7}{|l|}{ Trophic } \\
\hline Herbivore density & Herb & no. $/ \mathrm{m}^{2}$ & 0.24 & 0.03 & 0.10 & 0.36 \\
\hline Detritivore & $\mathrm{D}$ & no. $/ \mathrm{m}^{2}$ & 0.05 & 0.02 & 0.00 & 0.23 \\
\hline \multicolumn{7}{|l|}{ Reproductive } \\
\hline Nest-associate density & NA & no. $/ \mathrm{m}^{2}$ & 0.50 & 0.20 & 0.01 & 1.78 \\
\hline Non-guarder density & NG & no. $/ \mathrm{m}^{2}$ & 0.24 & 0.05 & 0.02 & 0.51 \\
\hline \multirow{2}{*}{\multicolumn{7}{|c|}{$\begin{array}{l}\text { Macroinvertebrate } \\
\text { Summary }\end{array}$}} \\
\hline & & & & & & \\
\hline Total density & MacDen & no. $/ \mathrm{m}^{2}$ & 677 & 134 & 161 & 1421 \\
\hline Midge density & Midge & no. $/ \mathrm{m}^{2}$ & 175 & 37 & 54 & 441 \\
\hline \multicolumn{7}{|l|}{ Trophic } \\
\hline Shredder density & SH & no. $/ \mathrm{m}^{2}$ & 11 & 6 & 0 & 65 \\
\hline Scraper density & $\mathrm{SC}$ & no. $/ \mathrm{m}^{2}$ & 178 & 49 & 11 & 474 \\
\hline Collector-gatherer density & CG & no. $/ \mathrm{m}^{2}$ & 192 & 53 & 22 & 538 \\
\hline Collector-filterer density & $\mathrm{CF}$ & no. $/ \mathrm{m}^{2}$ & 90 & 19 & 11 & 172 \\
\hline Predator & $\mathrm{P}$ & no. $/ \mathrm{m}^{2}$ & 30 & 10 & 0 & 97 \\
\hline
\end{tabular}

Notes: Land cover is the percentage of zone in a category. Corr. represents 100-m riparian corridor; WS represents whole watershed. Travel-time zones (TZZs) are shown as 60, 90, and 120 minutes for forest, agricultural, and urban landscapes. Data presented are measures of central tendency and variation for entities derived from measures across 10 third- or fourth-order stream systems in the southern Appalachian mountains.

$\dagger$ Unitless. 

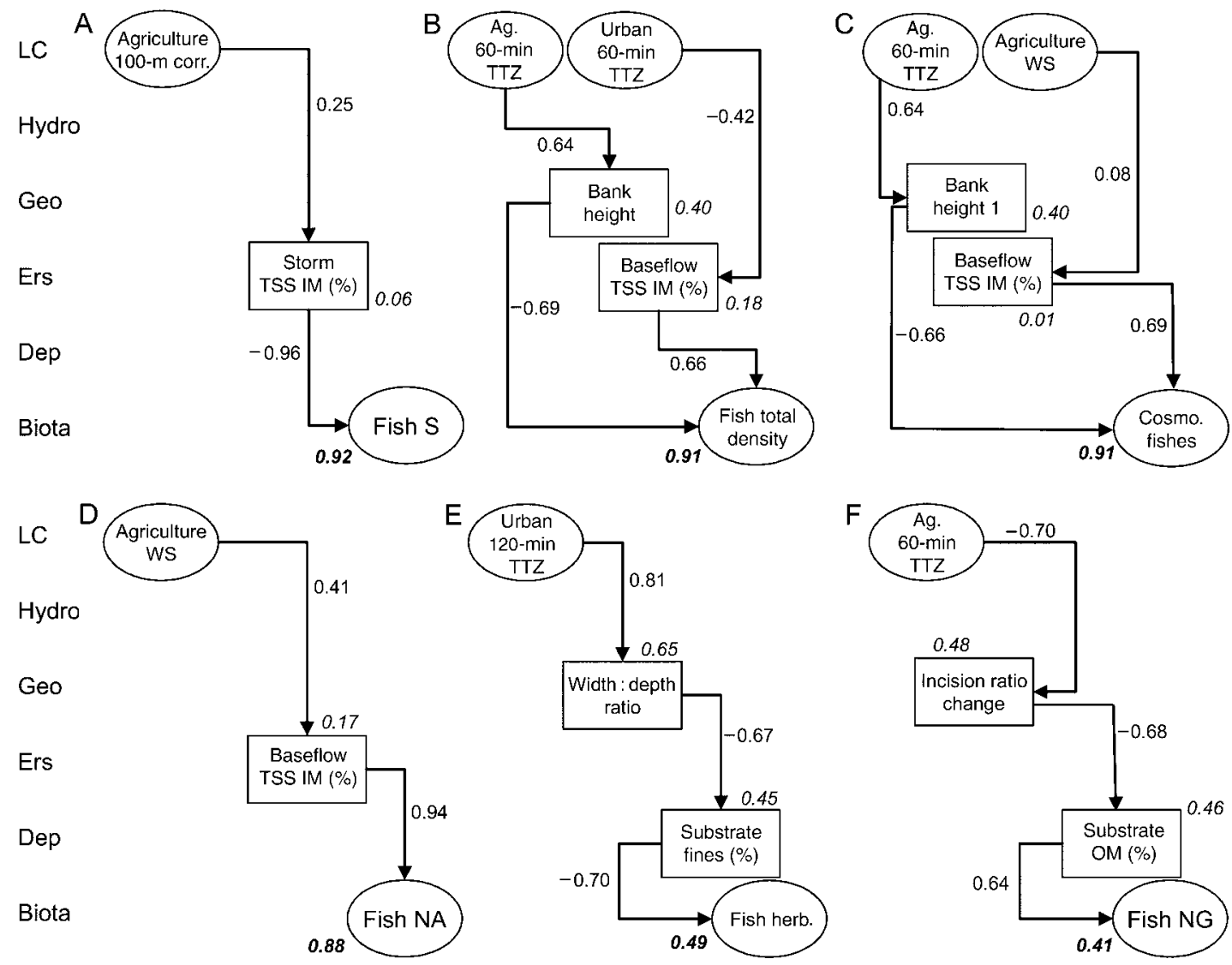

FIG. 3. Path diagrams quantifying land-cover cascades for fish responses. Individual path diagrams are discussed in Results: Significant land-cover cascades: Fish responses. Ovals indicate stimuli or responses, and boxes indicate entities. Boldface italicized numbers near responses are multiple correlation coefficients (analogous to $r^{2}$ ) describing the overall multivariate strength of the preceding model in explaining the variance in the associated response. Italicized numbers near entities are multiple correlation coefficients explaining the predictive ability of the model portion of the LCC preceding that entity. Numbers along path arrows are standardized path coefficients (analogous to correlation coefficients) and are direct bivariate effects (Appendix C). Abbreviations on the left indicate element levels: LC, land cover (stimulus); Hydro, hydrologic; Geo, geomorphic; Ers, erosional; Dep, depositional. Biotic responses are density estimates (no. $/ \mathrm{m}^{2}$ ). Other abbreviations: corr., riparian corridor; cosmo., cosmopolitan; Fish S, fish taxa richness; herb., herbivore; Fish NA, fish nest associates; Fish NG, fish non-guarder; TTZ, travel-time zone (60, 90, or 120 minutes for urban and agricultural [Ag.] landscapes); TSS, total suspended solids; IM, inorganic matter; OM, organic matter; WS, whole watershed.

and midge density. On the other hand, agriculture had a positive effect on total, shredder, and CG density. Both scraper (SC) and collector-gatherer (CG) densities were positively influenced by urban land cover. All significant LCCs predicting invertebrate responses included the geomorphic element represented by entities like bank height, width : depth ratio, and incision ratio change. The erosional element was not included in any macroinvertebrate LCC. At the same time, the depositional element and associated substrate entities were present in six of seven LCCs. The fifth element, biota, was important in two models, where cosmopolitan fish density influenced macroinvertebrate taxa richness and fish nest-associate density influenced midge density (Fig. 4).

The strongest macroinvertebrate LCC, predicting variance in $\mathrm{CF}$ density (chi-square $P$ value $>0.7$ ), was composed of one first-order and two second-order cascades (Fig. 4C). The CF LCC quantified how higher agriculture and urban land uses led to lower CF density. Hydrologic, geomorphic, and substrate elements were important in explaining $42 \%$ of the variation in $\mathrm{CF}$ density among streams along three unique pathways linking land cover to CF. Higher agriculture in 120-min TTZs led to lower rating curve slope or smaller increases in discharge with a rise in stage height $(-0.67)$. Lower rating curve slopes facilitated smaller substrate particle size $\left(\mathrm{D}_{50} ;+0.64\right)$, which ultimately was related to higher $\mathrm{CF}$ density. At the same time, lower urban land use near streams (120-min TTZs) was related to narrower, deeper streams (i.e., lower width: depth ratio; 0.81), that either influenced $\mathrm{CF}$ directly by causing a decline in density ( -0.71 , second-order cascade) or increased CF density through its influence on particle size $(+0.36,54 \%$ of 

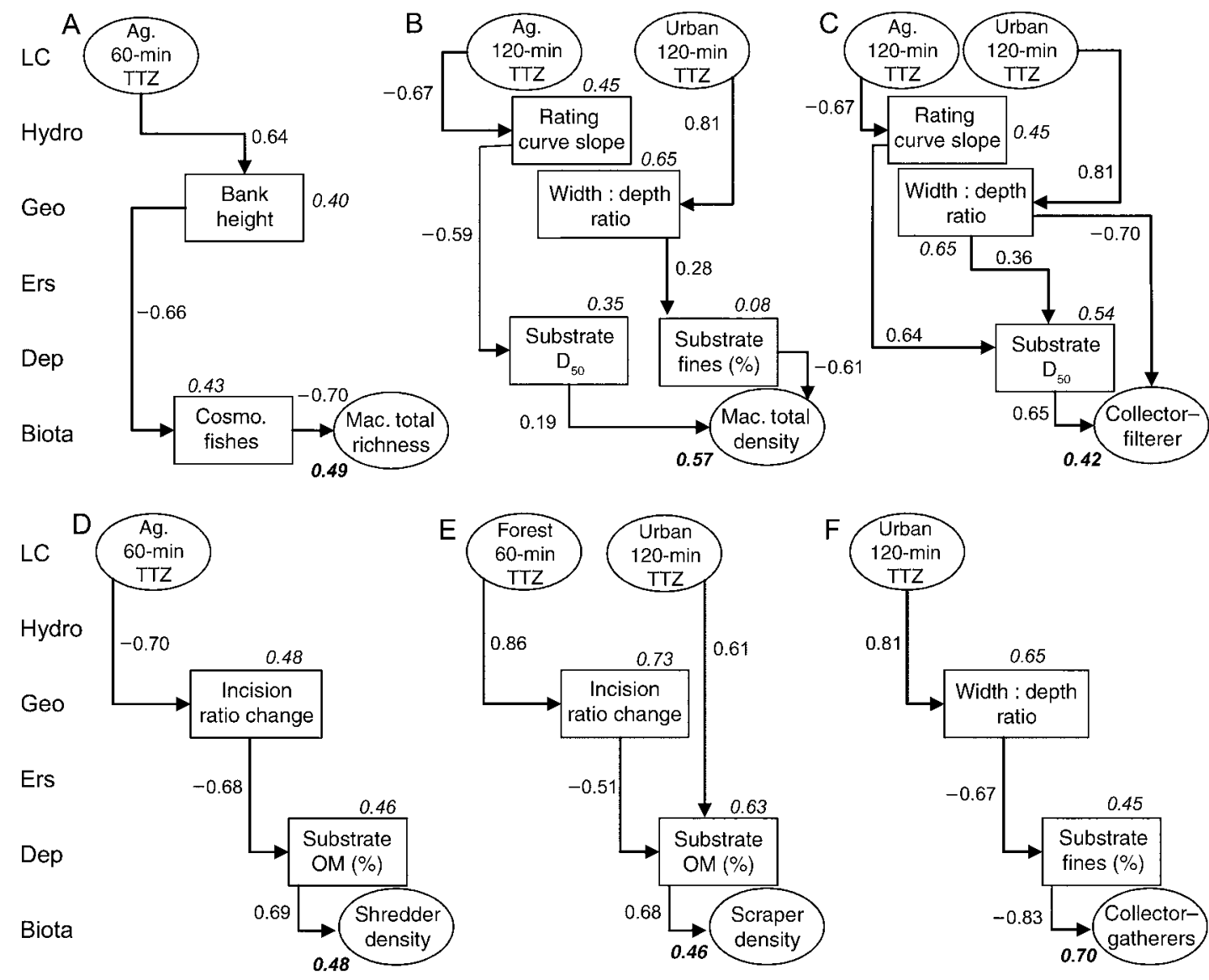

$F$
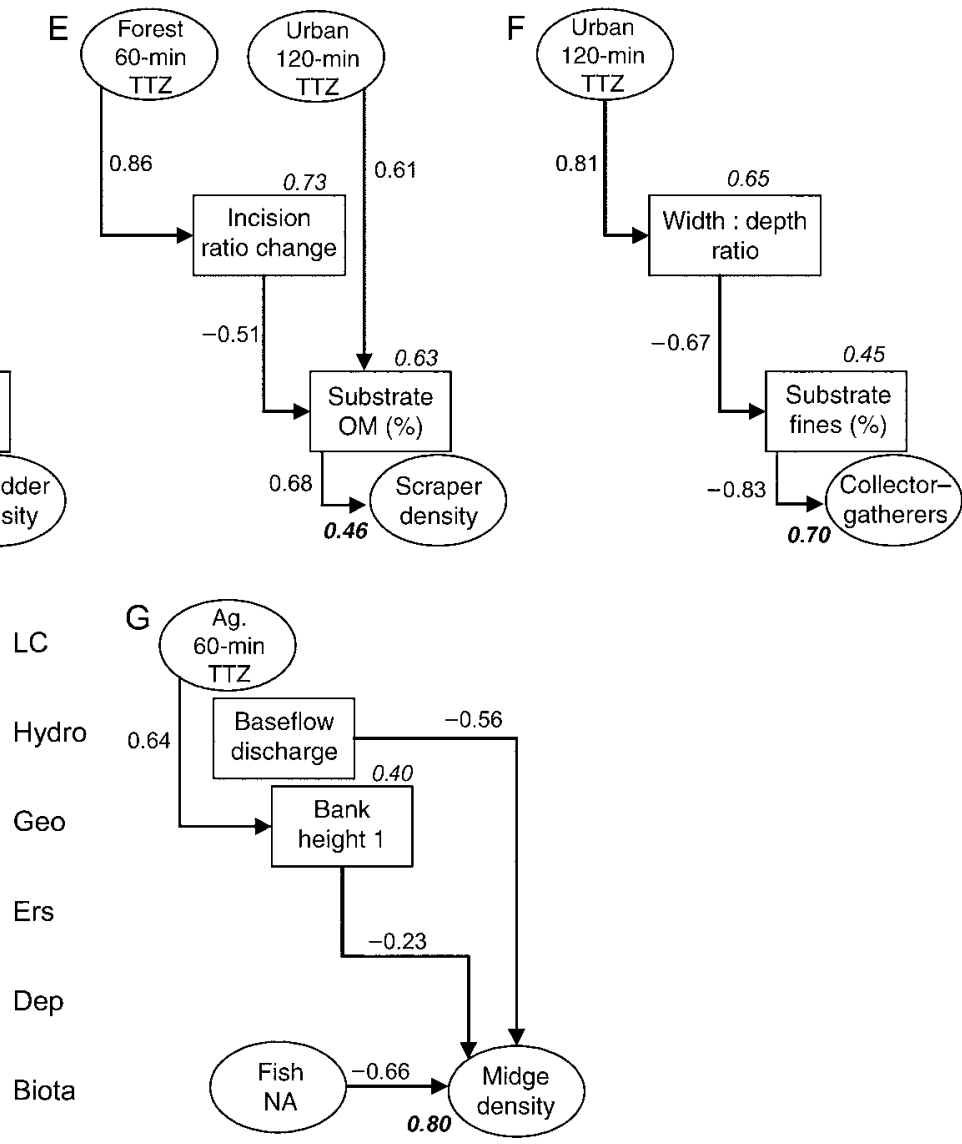

FIG. 4. Path diagrams quantifying land-cover cascades for macroinvertebrate (Mac.) responses. Individual path diagrams are discussed in Results: Significant land-cover cascades: Macroinvertebrate responses. "Collector-gatherer" and "Collector-filterer" refer to densities. See Fig. 3 for an explanation of values and other abbreviations.

variation) and its influence ( +0.65$)$ on $\mathrm{CF}$ density (thirdorder cascade; Fig. 4C).

Other macroinvertebrate LCCs, though less significant, provided useful information. Variance in macroinvertebrate taxa richness was explained by an LCC stimulated by agriculture (60-min TTZ) as translated by bank height and cosmopolitan fish density (Fig. 4A). Macroinvertebrate total density was explained by two second-order cascades that collectively accounted for $57 \%$ of the variation in total density among streams (Fig. 4B). Increased agriculture and decreased urban land cover decreased the slope of the rating curve (hydrologic element) and width:depth ratio (geomorphic element), respectively. Particle size was influenced by these hydrologic and geomorphic elements that combined to influence particle size. Increased particle 
TABLE 3. Indices of model fit for significant land-cover cascades (LCCs) identified by path analysis.

\begin{tabular}{|c|c|c|c|c|c|}
\hline \multirow[b]{2}{*}{ Model } & \multicolumn{3}{|c|}{ Chi-square } & \multirow{2}{*}{$\begin{array}{c}\text { Root mean square error } \\
\text { of approximation } \\
\text { (RMSEA) }\end{array}$} & \multirow{2}{*}{$\begin{array}{l}\text { Normed fit } \\
\text { index (NFI) }\end{array}$} \\
\hline & $\chi^{2}$ & $\mathrm{df}$ & $P$ & & \\
\hline \multicolumn{6}{|l|}{ Fish LCCs } \\
\hline Taxa richness & 3.597 & 1 & 0.06 & 0.537 & 0.805 \\
\hline Total density & 1.204 & 3 & 0.75 & 0.00 & 0.943 \\
\hline Cosmopolitan density & 7.580 & 6 & 0.27 & 0.171 & 0.731 \\
\hline Non-guarder density & 6.236 & 3 & 0.10 & 0.346 & 0.724 \\
\hline Nest-associate density & 1.999 & 1 & 0.16 & 0.333 & 0.872 \\
\hline Herbivore density & 4.085 & 6 & 0.25 & 0.200 & 0.836 \\
\hline \multicolumn{6}{|l|}{ Macroinvertebrate LCCs } \\
\hline Taxa richness & 4.084 & 3 & 0.25 & 0.200 & 0.765 \\
\hline Total density & 21.811 & 14 & 0.08 & 0.249 & 0.727 \\
\hline Shredder density & 5.366 & 3 & 0.15 & 0.296 & 0.764 \\
\hline Scraper density & 5.635 & 6 & 0.47 & 0.00 & 0.840 \\
\hline Collector-filterer density & 6.738 & 10 & 0.75 & 0.00 & 0.818 \\
\hline Collector-gatherer density & 6.995 & 3 & 0.07 & 0.385 & 0.785 \\
\hline Midge density & 9.727 & 6 & 0.14 & 0.263 & 0.652 \\
\hline
\end{tabular}

Notes: $P$ values are presented to facilitate comparison among indices with respective significance cutoff levels (see Methods: Statistical analyses: Identifying appropriate cascade models).

size (as decreased percentage fines, -0.61 ; or increased $\left.\mathrm{D}_{50},+0.19\right)$ was related to increased total density while the LCC jointly explained $57 \%$ of the variation in macroinvertebrate total density.

Shredder, scraper, and collector-gatherer density were predicted by LCCs that organized stimuli, geomorphic, and depositional entities. Shredder density was influenced by near-stream agriculture, change to bank incision ratio, and substrate OM (Fig. 4D). Variation in scraper density among systems was explained by a forest stimulus leading to a change in incision ratio and both forest and urban stimuli altering substrate $\mathrm{OM}$ (Fig. 4E). Urban land cover was also the stimulus explaining the variance in collector-gatherer density which was translated by geomorphic (width: depth ratio) and depositional (substrate percentage of fines) entities (Fig. 4F). Finally, variation in midge density was explained by a first-order LCC (Fig. 4G). As in other LCC models, the near-stream agricultural stimulus was correlated $(+0.64)$ to bank height (geomorphic) and bank height was negatively correlated $(-0.23)$ to midge density. Baseflow discharge was negatively correlated to midge density $(-0.56)$, but no land-cover stimulus was associated with this entity. Similarly, higher fish nestassociate density negatively influenced midge density $(-0.66)$ but no land-cover entity stimulated nestassociate density. Together, higher agriculture, higher baseflow discharge, and higher density of fish NA explained $80 \%$ of the variation in midge density observed among study streams.

\section{DisCUSSION \\ Responses}

Fish assemblage responses.-Of all LCCs predicting fish responses, total density (Fig. 3B) was clearly the strongest cascade due to explanatory capacity and quality of fit to our data. The vast majority of changes in fish density were explained by the influence of agriculture and/or urbanization on geomorphic (stream channelization) and erosional (suspended-sediment concentration) entities. Channelization and suspended sediments have been shown to increase with anthropogenic disturbance and are commonly reported in the literature as being proximate influences lowering fish density (Angermeier and Karr 1986, Wang et al. 2001, Sutherland et al. 2002). The LCC approach ties these intermediate entities to watershed development, its influence on stream geomorphology, sediment transport, and fish-community properties.

In general, LCC models showed that fish diversity and density were impaired by near-stream agriculture. The LCC models provided more information than previous studies by identifying key mediating variables involved in the transfer of land-use disturbance to fishes that included geomorphic (channel form as channelization), erosional (suspended inorganic sediments promoted by agriculture), depositional (substrate size as percentage of fine substrates and higher FBOM concentration) elements. Our fish models suggested that near-stream anthropogenic land use induced geomorphic changes (particularly channel incision) that further created substrate conditions suitable for retaining sand, silt, and fine organic matter $(\mathrm{OM})$. The combination of these changes in an LCC design predicted decreased fish density and diversity.

Macroinvertebrate assemblage responses.-Similar to the LCC models developed for fish, a single LCC predicting macroinvertebrate communities was clearly the strongest, based upon explanatory power (Fig. 4C) and goodness-of-fit (Table 3). In our model, channelized streams were associated with finer substrates and a decrease in collector-filterer (CF) trophic groups. 
Whereas other studies have shown that functional feeding groups (FFGs) are related to land cover, our CF LCC model suggests that the combination of impervious surfaces and associated hydrologic changes, including shallower streams and the washing-out of fine substrates, were favorable to collector-filterers (Danger and Robson 2004).

Macroinvertebrates responded to depositional entities more often than erosional entities. Macroinvertebrate density and diversity are often linked to habitat heterogeneity, and our LCCs support this contention (Resh and Rosenberg 1984). Further, we show that agriculture simulates a decrease in substrate size and an increase in substrate OM. The LCC approach broadens the relationship between invertebrates and substrate by suggesting that agriculture and erosion may lead to lower substrate particle size. Relationships like these will enable identification of key variables involved in disturbance propagation and provide more resolution toward identifying the mechanisms responsible.

Macroinvertebrates were influenced by depositional entities, whereas fish responded more often to erosional entities. There also appeared to be a relationship between land-use stimuli and erosional and depositional responses. Agricultural stimuli more often induced deeper channels and increased sediment loads compared to urban stimuli. On the other hand, urban stimuli reduced suspended sediment concentration, which was favorable to fish. The urban literature suggests that increased impervious surface cover alters watershed hydrology and reduces the erosional sediments in streams (Morse et al. 2003, Wang and Kanehl 2003). Our LCC models suggest that urban stimuli induce lower suspended sediments compared to agriculture and provide preferential conditions for fish.

Typically, fish LCCs were second order, requiring one intermediate entity to propagate disturbance, whereas macroinvertebrate LCCs were generally third order. The most complex LCC predicted macroinvertebrate community structure and contained multiple cascades including two third-order and one first-order cascade. Using the cascade framework and the two strongest LCCs, we identified key intermediate abiotic variables that may participate in mechanistic relationships between land-cover disturbance and biotic responses and address the identity and character of these two LCC models later in the discussion.

\section{Stimuli}

More than half the significant LCC models included agricultural land use as the sole stimulus, whereas two models included only urban stimuli. In four LCC models, including the two strongest LCCs, both urban and agricultural stimuli were included and likely reflected a negative correlation between these land-cover types. Burcher and Benfield (2006) showed that study systems were undergoing rural development in formerly agricultural areas converted to homes, roads, and other infrastructure. The co-occurrence of agricultural and urban stimuli reflected in LCCs likely reflected this transition of rural areas near Asheville, North Carolina, USA, to more urbanized land uses (Meyer and Turner 1992, United Nations 1999). In other words, urban land use increased near our study streams as agricultural stimuli decreased. As a result, agricultural and urban stimuli affected systems differentially, and we could not differentiate between these influences when they cooccurred in the same LCC. In general, agriculture and urban land uses are associated with biotic impairment. The LCC conclusions support this contention and provide insight toward the key variables and associated mechanisms responsible for propagation.

\section{Entities}

Hydrologic entities were only important in three macroinvertebrate LCCs and absent from fish models. Many researchers have suggested that hydrologic dynamics organize watershed-scale stream disturbance (Friedman et al. 1996, Walling 1998, Croke et al. 1999, Gomi et al. 2002), and we attempted to quantify as many hydrologic entities as possible. However, hydrologic phenomena are notoriously difficult to quantify due to the varying nature, timing, and intensity of storms (Poff and Ward 1989). Significant hydrologic alteration likely occurs during catastrophic storms, which we were unable to quantify (Vidon and Hill 2004, Doyle et al. 2005) and several of which occurred during our study period, an observation that was supported by USGS gauging stations located on the mainstem Ivy Creek and near the confluence of Cane Creek on the mainstem French Broad River (USGS data, available online). ${ }^{2}$ Changes to bank height, incision ratio, and discharge-stage rating curves in our study streams suggested that watershed hydrologic dynamics played an important role in influencing biotic assemblages (Gaines and Denny 1993), although LCC models rarely captured this relationship (Pickup and Warner 1976). Though LCCs did not implicate hydrologic processes as contributing to disturbance propagation, the ramifications of hydrologic processes certainly are important in linking land use to other elements and biota.

Stream geomorphology and geomorphic entities linked land-cover stimuli to biotic responses in all macroinvertebrate and four of seven fish LCCs. Bank height, width: depth ratio, and incision-ratio changes reflect changes to stream-channel morphology that have been shown to influence stream biota in other studies (Poff and Allan 1995, Walling 1998, Vidon and Hill 2004). Following the logic of the LCC, geomorphic entities should be influenced by hydrology and future research should focus on hydrologic features manifested during stormflow to capture this relationship.

\footnotetext{
${ }^{2}\langle$ http://waterdata.usgs.gov/nwis/rt $\rangle$
} 
Erosional metrics were critical entities in four of six fish LCCs but absent from macroinvertebrate models. This suggests that fish are influenced by suspended sediment movement whereas macroinvertebrates did not respond to erosional entities. Other studies have demonstrated an erosional influence on fish by suspended sediments (Berkman and Rabeni 1987, Roth et al. 1996, Trimble and Crosson 2000, Nerbonne and Vondracek 2001). Macroinvertebrates are likely more tolerant to suspended sediments because of their close association to the substrate and lower exposure to water column dynamics (Angradi 1999).

Conversely, depositional entities were more important than erosional entities in five of seven macroinvertebrate LCCs occurring in only two of six fish models. Macroinvertebrates are closely associated with substrate diversity and density is often strongly correlated to substrate size and embeddedness (Gurtz and Wallace 1984, Wohl et al. 1995, Angradi 1999). Some fishes are influenced by substrate type, although many species can manipulate substrate condition through moving or cleaning behaviors (Jenkins and Burkhead 1994). In our study systems, substrate composition is likely less critical to fish life cycles than macroinvertebrate life cycles. Our macroinvertebrate LCCs support the contention that density and diversity are influenced by depositional entities (substrate size, percentage of fines, percentage of OM) but further show that substrate condition is affected by stream geomorphic and hydrologic entities that are altered by landscape condition (e.g., agricultural stimuli).

\section{SYNTHESIS}

Cascade models successfully linked land-cover-disturbance stimuli to biotic responses through a series of intermediate abiotic links. Unlike bivariate comparisons, land-cover cascade (LCC) models offered insight into relationships among variables in the context of how landscape disturbance is propagated to ultimately influence organisms. The LCC also identified land-cover metrics that represent anthropogenic stimuli that ultimately induce biotic alteration in streams. Moreover, the LCC framework quantified relationships between land-cover and biotic responses. The existence of LCCs suggests that disturbance can be propagated across spatial scales via translation among intermediate entities. The cascade approach is therefore useful in complex systems spanning broad spatial and temporal scales. Furthermore, aspects of stream communities appear to be appropriate tools for identifying the translation of land-cover disturbance. Biomonitoring efforts can be improved by results from the LCC. The LCC approach identified two useful response metrics for bioassessment research. Many have suggested that ecosystem indicators can be used to interpret the ecosystem condition; we provide two: fish total density and macroinvertebrate collector-filterer (CF) that are useful in bioassessment studies (Lorenz et al. 1997).
The LCC linked land-cover disturbance to stream biotic responses and illustrated how an alternative statistical approach (i.e., path analysis vs. traditional regression) can generate a significant contribution to an existing body of research. Similarly, using the cascade approach in complex systems may be more relevant than traditional multivariate approaches because complexity typically involves experimental hurdles that are difficult to address using traditional Fisherian statistics (Carpenter 1989, Shipley 2000). Using our approach, both analytical techniques were used in search of complimentary information that provides a wider array of information from which to draw conclusions. This manuscript represents the first attempt to link land cover to community responses through the hierarchy of intermediate entities. In other systems, entities could vary depending on what is known about existing land cover: biotic relationships and appropriate spatial scales unique to other systems. Others interested in mechanistic relationships among ecosystem components at different spatial scales will likely benefit from a cascade approach that allows linking of related variables in a hierarchical structure, and this may be relevant to existing cascade paradigms (Carpenter et al. 1985, Galloway et al. 2003).

\section{ACKNOWLEDGMENTS}

This research was supported by NSF Grant DEB-9632854 and DEB-0218001 awarded to the Coweeta LTER program. Other support came from Sigma $\mathrm{Xi}$ and the Virginia Tech Graduate School. The authors also thank A. Braccia, E. N. J. Brookshire, G. Poole, and E. Sokol for their discussions and reviews during the development of this idea.

\section{Literature Cited}

Allan, J. D. 2004. Landscapes and riverscapes: the influence of land use on stream ecosystems. Annual Review of Ecology and Systematics 3:257-284.

Angermeier, P. L., and J. R. Karr. 1986. Applying an index of biotic integrity based on stream-fish communities: considerations in sampling and interpretation. North American Journal of Fisheries Management 6:418-429.

Angradi, T. R. 1999. Fine sediment and macroinvertebrate assemblages in Appalachian streams: a field experiment with biomonitoring applications. Journal of the North American Benthological Society 18:49-66.

Arbuckle, J. A. 2003. Amos 5.0 update to the Amos user's guide. Smallwaters, Chicago, Illinois, USA.

Berkman, H. E., and C. F. Rabeni. 1987. Effect of siltation on stream fish communities. Environmental Biology of Fishes 18:285-294.

Braatz, D. A. 1961. The single-stage sampler for suspended sediment. Subcommittee on sedimentation, inter-agency committee on water resources. Report number 13. Minneapolis, Minnesota, USA.

Burcher, C. L. 2005. Biotic and abiotic responses to rural development and legacy agriculture by southern Appalachian streams. Dissertation. Virginia Polytechnic Institute and State University, Blacksburg, Virginia, USA.

Burcher, C. L., and E. F. Benfield. 2006. Physical and biological responses of streams to suburbanization of historically agricultural streams. Journal of the North American Benthological Society 25:356-369.

Carpenter, S. R. 1989. Replication and treatment strength in whole-lake experiments. Ecology 70:453-463. 
Carpenter, S. R., J. F. Kitchell, and J. R. Hodgson. 1985. Cascading trophic interactions and lake productivity. BioScience 35:634-639.

Croke, J., P. Hairsine, and P. Fogarty. 1999. Runoff generation and re-distribution in logged eucalyptus forests, southeastern Australia. Journal of Hydrology 216:56-77.

Cuffney, T. F., M. R. Meador, S. D. Porter, and M. E. Gurtz. 2000. Responses of physical, chemical and biological indicators of water quality to a gradient of agricultural land use in the Yakima River basin, Washington. Environmental Monitoring and Assessment 64:259-270.

Danger, A. R., and B. J. Robson. 2004. The effects of land use on leaf-litter processing by macroinvertebrates in an Australian temperate coastal stream. Aquatic Sciences 66:296-304.

Downes, B. J., L. A. Barmuta, P. G. Fairweather, D. P. Faith, M. J. Keough, P. S. Lake, B. D. Mapstone, and G. P. Quinn. 2002. Monitoring ecological impacts: concepts and practice in flowing water. Cambridge University Press, New York, New York, USA.

Doyle, M. W., E. H. Stanley, D. L. Strayer, R. B. Jacobson, and J. C. Smith. 2005. Effective discharge analysis of ecological processes in streams. Water Resources Research 41:W11411.

Etnier, D. A., and W. C. Starnes. 1993. The fishes of Tennessee. University of Tennessee Press, Knoxville, Tennessee, USA.

Friedman, J. M., W. R. Osterkamp, and W. M. Lewis. 1996. Channel narrowing and vegetation development following a Great Plains flood. Ecology 77:2167-2181.

Frissell, C. A., W. J. Liss, C. E. Warren, and M. D. Hurley. 1986. A hierarchical framework for stream habitat classification: viewing streams in a watershed context. Environmental Management 10:199-214.

Gaines, S. D., and M. W. Denny. 1993. The largest, smallest, highest, lowest, longest, and shortest: extremes in ecology. Ecology 74:1677-1692.

Galloway, J. N., J. D. Aber, J. W. Erisman, S. P. Seitziger, R. W. Howarth, E. B. Cowling, and B. J. Cosby. 2003. The nitrogen cascade. BioScience 53:341-356.

Gomi, T., R. C. Sidle, and J. S. Richardson. 2002. Understanding processes and downstream linkages of headwater systems. BioScience 52:905-916.

Gurtz, M. E., and J. B. Wallace. 1984. Substrate-mediated responses of stream invertebrates to disturbance. Ecology 65: $1556-1569$.

Harding, J. S., E. F. Benfield, P. V. Bolstad, G. S. Helfman, and E. B. D. Jones. 1998. Stream biodiversity: the ghost of land use past. Proceedings of the National Academy of Science (USA) 95:14843-14847.

Harding, J. S., R. G. Young, J. W. Hayes, K. A. Shearer, and J. D. Stark. 1999. Changes in agricultural intensity and river health along a river continuum. Freshwater Biology 42:345357.

Herman, K. A. 1996. Southern Appalachian Assessment (SAA) GIS Database on CD-ROM. Third edition. Southern Appalachian man and the biosphere (SAMAB) program. Norris, Tennessee, USA.

Hynes, H. B. N. 1975. The stream and its valley. Internationale Vereingigung fuer Theoretische und Angewandte Limnologie Verhandlungen 19:1-15.

Jacobson, R. B., S. R. Femmer, and R. A. McKenney. 2001. Land-use changes and the physical habitat of streams - a review with emphasis on studies within the U.S. Geological Survey federal-state cooperative program. USGS Circular 1175.

Jenkins, R. E., and N. M. Burkhead. 1994. Freshwater fishes of Virginia. American Fisheries Society, Bethesda, Maryland, USA.

Lake, P. S. 2000. Disturbance, patchiness, and diversity in streams. Journal of the North American Benthological Society 19:573-592.
Lamouroux, N., N. L. Poff, and P. L. Angermeier. 2002. Intercontinental convergence of stream-fish community traits along geomorphic and hydraulic gradients. Ecology 83:1792-1807.

Lee, J. H., and K. W. Bang. 2000. Characterization of urban stormwater runoff. Water Research 6:1773-1780.

Likens, G. E., F. H. Bormann, R. S. Pierce, and W. A. Reiners. 1984. Recovery of a deforested ecosystem. Science 199:492496.

Lorenz, C. M., G. M. Van Dink, G. M. Van Hattum, and W. B. Cofino. 1997. Concepts in river ecology: implications for indicator development. Regulated Rivers: Research and Management 13:501-516.

Merritt, R. W., and K. W. Cummins. 1996. An introduction to the aquatic insects of North America. Third edition. Kendall/ Hunt Publishing, Dubuque, Iowa, USA.

Meyer, W. B., and B. L. Turner. 1992. Human population growth and global land-use/cover change. Annual Review of Ecology and Systematics 23:39-61.

Montgomery, D. R. 1999. Process domains and the river continuum. Journal of the American Water Resources Association 35:397-410.

Morse, C. C., A. D. Huryn, and C. Cronan. 2003. Impervious surface area as a predictor of the effects of urbanization on stream insect communities in Maine, USA. Environmental Monitoring and Assessment 89:95-127.

Nerbonne, B. A., and B. Vondracek. 2001. Effects of local land use on physical habitat, benthic macroinvertebrates, and fish in the Whitewater River, Minnesota, USA. Environmental Management 28:87-99.

Pickup, G., and R. F. Warner. 1976. Effects of hydrologic regime on magnitude and frequency of dominant discharge. Journal of Hydrology 29:51-75.

Poff, N. L., and J. D. Allan. 1995. Functional organization of stream fish assemblages in relation to hydrological variability. Ecology 76:606-627.

Poff, N. L., and J. V. Ward. 1989. Implications of streamflow variability and predictability for lotic community structure: a regional analysis of streamflow patterns. Canadian Journal of Aquatic Sciences 46:1805-1818.

Resh, V. H., and D. M. Rosenberg. 1984. The ecology of aquatic insects. Praeger, New York, New York, USA.

Richards, C., L. B. Johnson, and G. E. Host. 1996. Landscapescale influences on stream habitats and biota. Canadian Journal of Fisheries and Aquatic Sciences 53:295-311.

Roth, N. E., J. D. Allan, and D. L. Erickson. 1996. Landscape influences on stream biotic integrity assessed at multiple spatial scales. Landscape Ecology 11:141-156.

Shipley, B. 2000. Cause and correlation in biology. A user's guide to path analysis, structural equations, and causal inference. Cambridge University Press, Cambridge, UK.

Sponseller, R. S., H. M. Valett, and E. F. Benfield. 2001. Relationships between land-use, spatial scale, and stream macroinvertebrate communities. Freshwater Biology 46: 1409-1424.

Sutherland, A. B., J. L. Meyer, and E. P. Gardiner. 2002. Effects of land cover on sediment regime and fish assemblage structure in four southern Appalachian streams. Freshwater Biology 47:1791-1805.

Trimble, S. W., and P. Crosson. 2000. U.S. soil erosion rates: myths and reality. Science 289:248-250.

United Nations. 1999. World urbanization project: the 1999 revision. New York: Population Division, Department of Economic and Social Affairs, United Nations. New York, New York, USA.

USCB (U.S. Census Bureau) 2002. 2000 census of population and housing. Summary population and housing statistics, PHC 1-35, North Carolina. Washington, D.C., USA.

USDI (U.S. Department of the Interior). 2002. United States Geological Survey. Draft. Multi-resolution land characteris- 
tics (MRLC) consortium land-cover data set. Washington, D.C., USA.

Vidon, P. G. F., and A. R. Hill. 2004. Landscape controls on the hydrology of stream riparian zones. Journal of Hydrology 292:210-228.

Walling, D. E. 1998. Erosion and sediment yield research-some recent perspectives. Journal of Hydrology 100:113-141.

Wang, L. H., and P. Kanehl. 2003. Influences of watershed urbanization and instream habitat on macroinvertebrates in cold water streams. Journal of the American Water Resources Association 39:1181-1196.

Wang, L. H., J. Lyons, P. Kanehl, and R. Bannerman. 2001. Impacts of urbanization on stream habitat and fish across multiple spatial scales. Environmental Management 28:255266.
Ward, J. V. 1989. The four-dimensional nature of lotic ecosystems. Journal of the North American Benthological Society $8: 2-8$.

Waters, T. F. 1995. Sediment in streams: sources, biological effects, and control. American Fisheries Society Monograph 7:169-180.

Wear, D. N., and P. Bolstad. 1998. Land-use changes in southern Appalachian landscapes: Spatial analysis and forecast evaluation. Ecosystems 1:575-594.

Wohl, D. L., J. B. Wallace, and J. L. Meyer. 1995. Benthic macroinvertebrate community structure, function and production with respect to habitat type, reach and drainage basin in the southern Appalachians (USA). Freshwater Biology 34:447-464.

\section{APPENDIX A}

List of stimuli considered in ecological cascades (Ecological Archives E088-014-A1).

\section{APPENDIX B}

Cascade elements and their associated entities (Ecological Archives E088-014-A2).

\section{APPENDIX C}

Set of pairwise comparisons (i.e., direct effects) resulting from significant linear regressions (Ecological Archives E088-014-A3).

\section{APPENDIX D}

Abiotic and biotic response variables significant in at least one cascade path (Ecological Archives E088-014-A4).

\section{APPENDIX E}

Standardized direct, indirect, and total effects of land cover on each biotic response (Ecological Archives E088-014-A5). 